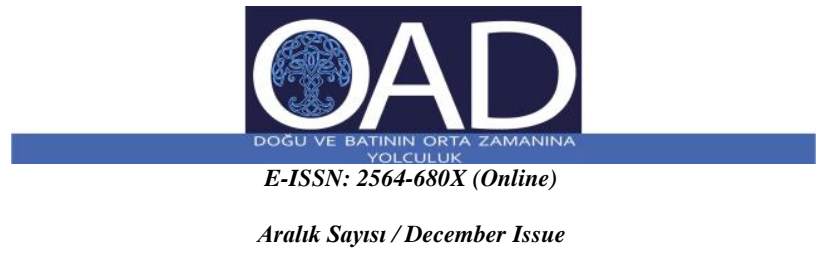

Yll 3, Sayı 2 / Year 3, Issue 2

ATIF BILGISI / REFERENCE INFORMATION

DEMIR, Hatice, “Bizans Dönemi Resimli Dinî El Yazmalarında Yeşeya Peygamber Tasvirleri”, Ortaçă̆ Araştırmaları Dergisi, III/II, Aralık 2020, s. 306-314.

Makale Türü: Sanat Tarihi Araştırma

DOI No: https://doi.org/10.48120/oad.824895

Geliş Tarihi / Received: 13 Kasım 2020 Online Yayın: 26 Aralık 2020
Kabul Tarihi / Accepted: 19 Aralı 2020 Published Online: 26 December 2020

\title{
Bizans Dönemi Resimli Dinî El Yazmalarında Yeşeya Peygamber Tasvirleri Hatice DEMIR ${ }^{1++}$
}

\author{
${ }^{1}$ Dr. Öğr. Gör., Kastamonu Üniversitesi Sosyal Bilimler Enstitüsü, KASTAMONU. \\ *haticedemir99@hotmail.com \\ +ORCID: 0000-0002-5801-5841
}

$\ddot{\boldsymbol{O}}_{\boldsymbol{z}}$ - Bu çalışmada, Kitab-1 Mukaddes’te adı geçen ve kitabı dört büyük peygamberden birisi olan Yeşeya peygamberin, Bizans dönemi resimli dinî el yazmalarındaki tasvirleri çalışılmıştır. Çalışma kapsamında, Yeşeya peygamberin tasvirleri gruplama yapılarak değerlendirilmiştir. Bu bağlamda, Yeşeya peygamberin tek başına tam sayfa kitap resmi örnekleri olabileceği gibi, diğer kutsal isimler ile birlikte de portre tasvirlerini görmek mümkündür. Yeşeya peygamberin Kitab-1 Mukaddes referanslı sahnelerde diğer kutsal isimlere eşlik ettiği resim örnekleri de mevcuttur. Hezekiel, Yusuf ve İsa bu kutsal isimlerden bazılarıdır. Kitab-1 Mukaddes temalı bir hikâyeyi anlatması adına, Yeşeya'nın Duası/İlahisi/Şarkısı/Rüyası tasvirleri kendisi ile en çok özdeşleşen sahnelerden biridir. Çalışma kapsamında, Yeşeya peygamberin tasvirlerini oluşturan son örnekler ise onun şehit edilişi ile ilgili olanlardır.

Anahtar Kelimeler-Yeşeya, Kitab-ı Mukaddes, El yazması, Büyük Peygamber

\section{The Prophet Isaiah's Images in Religious Manuscripts of Byzantine Era}

Abstract-In this study the depictions of the prophet Isaiah, one of the major prophets who had a book in Bible, in Byzantine manuscripts were studied. In the scope of the study, the depictions of the prophet Isaiah were evaluated by grouping. In this context, it is possible to see the depictions of the prophets Isaiah in two group of book illuminations. In first group he was depicted alone and in second group he accompanied to other holy figures such as Hezekiel, Joseph and Christ. For it mentions a Bible referenced theme, Isaiah's Prayer/Ode/Vision scenes are one of the mostly identified scenes of Christian illuminations by Isaiah. Within the scope of the study, the last examples that take part in the context are the ones related with his martyrdom.

Keywords - Isaiah, The Bible, Manuscript, Major Prophet 


\section{Giriș}

Kitab-1 Mukaddes'te dört büyük peygamber vardır. Bunlar; Yeşeya, Yeremya, Hezekiel ve Daniel'dir. Küçük peygamberler ise; Hoşea, Yoel, Amos, Ovadya, Yunus, Mika, Nahum, Habakkuk, Sefanya, Hagay, Zekariya ve Malaki'dir. 12 küçük peygamber çoğu zaman 12 'ler diye de anılmaktadır. Büyük peygamberlerin, büyük olarak anılmasının en önemli nedeni, kitaplarının ve kapsamlarının geniş olmasından kaynaklanır. Küçük peygamberler ise kitaplarının kapsamının daha dar olmasından dolayı böyle anılırlar ${ }^{1}$.

Adını İbranice "Yehova Kurtarır/Kurtuluştur" anlamına gelen

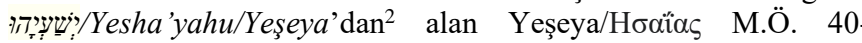
700'lerde Yahuda'nın Güney Krallığında yaşamış, Kitab-1 Mukaddes'in dört büyük peygamberinden birisi olarak kabul edilir ${ }^{3}$. 9 Mayıs Konstantinopolis sinaksarionuna göre şehit kabul edilmiş ve rölikleri, başkentte Blakhernai yakınlarındaki Aziz Laurentios Kilisesi'ne taşınmıştır ${ }^{4}$.

Yeşeya Peygamberin Kitabı'nın ${ }^{5}$ ana hatları şu şekildedir ${ }^{6}$; Yahuda ve Kudüs ile ilgili kehanetler (1-12. bölümler), diğer milletler aleyhine kehanetler (13-23. bölümler), kurtulus mesajları (24-27. bölümler), Misır ile ittifak konusunda uyarılar (28-35. bölümler), Hezekiel dönemi tarihi bilgiler (36-39. bölümler), güvenlik/refaha kavuşma mesajları (40-66. bölümler).

Yeşeya Peygamber, en çok kehanetleri ile bilinir. Kyrrhuslu Theodoretos (5. yüzyıl) onun kehanetleri arasında; İsa'nın geleceği, mucizeleri, havarilerin seçimi, çilesi, ölümü, dirilişi, göğe yükselişi ve milletlerin kurtuluşunu sıralar. Yeșeya Peygamberin, İsa ile ilgili kehanetlerinin dışında, İbrahim ve Davud'dan gelecek nimet ve rahmet gibi başka kehanetleri de mevcuttur? ${ }^{7}$.

\section{Bizans Dönemi Resimli Dinî El Yazmalarında Yeşeya Peygamber Tasvirleri}

Kitab-1 Mukaddes'in dört büyük peygamberinden birisi olan Yeșeya peygamberin, Bizans dönemi resimli dinî el yazmalarındaki tasvirlerini, şu alt başlıklar altında toplamak mümkündür.

\subsection{Yeşeya Peygamberin Tek Başına Tam Boy Tasvirleri}

Bizans dönemi resimli dinî el yazmalarında ${ }^{8}$, Yeşeya peygamberin tek ve grup halînde tasvirleri ile karşılaş1lır. Genelde psalter ve Peygamber Kitabı nüshalarında yer alan tasvir örneklerinden bazıları şu şekildedir: Tam sayfa resimlerinin yer aldığ 1 Peygamber Kitabı'ndan ilki, 10. yüzyılın ortasına tarihlenen Vat. Chig. R. VIII. 54, fol. 91 v. ${ }^{9}$ ve diğeri 13. yüzyıla tarihlenen Vat. gr. 1153 fol 84r.'dir ${ }^{10}$. 15. yüzyıla tarihlenen WAM 534 Saatler Kitabı'nda yine Yeşeya peygamberin tam sayfa resmi yer alır ${ }^{11}$. (Resim 1). Yeşeya peygamberin tek başına temsil edildiği tam sayfa örneklerinde; ayn kıyafetleri (khiton üzerine himation), atribüsü olan rulo ve uzun beyaz saçlı/sakallı olarak tasvir edildiği gözlemlenir. Özellikle uzun, beyaz

\footnotetext{
${ }^{1}$ Geniş bilgi için bk.
}

https://static1.squarespace.com/static/5006cb3dc4aa3dba77394b45/t/55b91f4 3e4b0b1e8d327ad1a/1438195523191/What+are+the+Major+Prophets+and+ Minor+Prophets\%3F.pdf

${ }^{2}$ Geniş bilgi için bk.

https://www.behindthename.com/name/isaiah\#: :text=Meaning $\% 20 \% 26 \% 2$ 0History,referring $\% 20$ to $\% 20$ the $\% 20 \mathrm{Hebrew} \% 20 \mathrm{God}$

${ }^{3}$ Earle, Ralph; Meet the Major Prophets, Beacon Hill Press, Kansas City, 1958, s. 7.

${ }^{4}$ Kazhdan, Alexander. P.; "Isaiah", The Oxford Dictionary of Byzantium, 2, New-York/Oxford: Oxford University Press 1991, s. 1013

${ }^{5}$ Toplam 66 bölümden olușan Yeșeya'nın Kitabı'nın tarihi olaylar zinciri ise şu şekildedir:

1. 1-39. bölümler; Güney Yahuda Krallığı’nın Asur tarafından tehdit edildiği günleri,

2. 40-55. bölümler; Asurlulardan sonra Babil tehdidi ve sürgününü,

3. 56-66. bölümler; sürgünden dönüs ve müjdeyi anlatır.

Geniş bilgi için bk. https://kutsal-kitap.net/bible/tr/index.php?mc=1\&sc=705

${ }^{6}$ Earle, Ralph; Meet the Major Prophets, Beacon Hill Press, Kansas City, 1958, s. 7. saçl1/sakallı tasvirleri ile yaşlı bir peygamber olarak tasvir edilen Yeşeya, çoğunlukla yine uzun, beyaz saçlı/sakallı Yeremya peygamber tasvirleri ile de karıştırılır.

Çalışma kapsamı için seçilen örnek, 15. yüzyıla tarihlenen ve WAM/Walters Sanat Müzesi'nde muhafaza edilen WAM 534/Saatler Kitabı'nda yer alan tam sayfa Yeseya Peygamber tasviridir. Tasvirde; Yeşeya Peygamber, yeşil khiton üzerine pembe himation giyimlidir ${ }^{12}$. Elinde bir peygamberlik atribüsü olarak açık bir rulo tutmaktadır. (Resim 1).

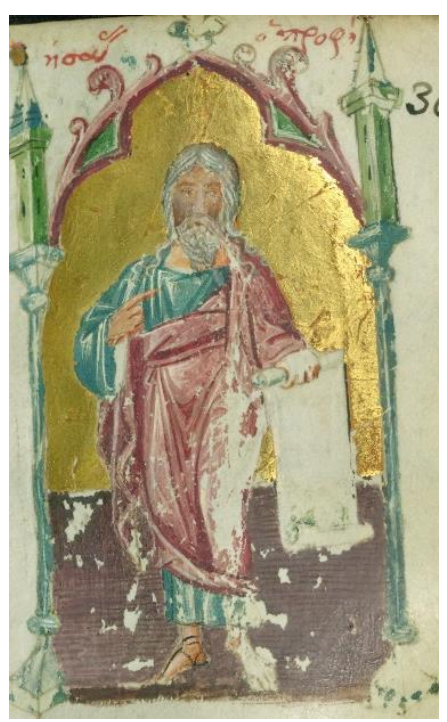

Resim 1: Yeşeya Peygamber Tam Boy Tasviri, WAM 534/Saatler Kitabı ( ${ }^{\circ}$ WAM/Walters Sanat Müzesi)

\subsection{Yeșeya Peygamberin Diğer Kutsal İsimler ile Birlikte Tasvirleri}

Bazı kitap resmi örneklerinde; Yeşeya peygamberin diğer kutsal isimler ile birlikte yer aldığg gözlemlenir.

Bu grup için seçilen ilk örnek; 11. yüzyıl Konstantinopolis üretimi olan Vat. gr. 755 'de yer alır ${ }^{13}$. Vat. gr. 755 fol. 1r.'de ayakta frontal duruşlu Yeşeya peygambere madalyon içerisinde portreleri olan dört kilise babas1 (Kaisarealı Basileos, Kyrrhuslu Theodoretos, İskenderiyeli Krill/Kyrillos ve Heraklialı Theodoros) eşlik etmektedir $^{14}$. Tasvirde, Yeșeya Peygamberin aynı kiyafetler (himation ve khiton) ve yaşlı bir figür olarak betimlendiği gözlemlenir. (Resim 2). Tasvirde; madalyonlar içerisinde yer alan

${ }^{7}$ Kazhdan, Alexander. P.; "Isaiah", The Oxford Dictionary of Byzantium, 2, New-York/Oxford: Oxford University Press 1991, s. 1013.

${ }^{8}$ Resimli el yazmalarının kökeni geniş bilgi için bk. Dinçer, Serdar Pınar; "El Yazmasının Kökeni ve Terminoloji Önerileri”, İdil, 5(23), 2016, 931-940.

${ }^{9}$ Görsel için bk. Vat. Chig. R. VIII. 54, fol. 91v. (Vatikan Apostolik Kütüphanesi) https://digi.vatlib.it/view/MSS_Chig.R.VIII.54

10 Görsel ve el yazmaları geniş bilgi için bk. Vat. gr. 1153 fol. 84r., (Vatikan Apostolik Kütüphanesi), https://digi.vatlib.it/view/MSS_Vat.gr.1153 .Vat. gr. 1154’te Yeșeya Peygamber'e dair atıflar görmek mümkündür.

11 Görsel için bk. (WAM/Walters Sanat Müzesi) https://art.thewalters.org/detail/14546

${ }^{12}$ Tasvirdeki renkler ve Yeşeya Peygamber tasviri, Venedik etkili Girit ekolü sergilemektedir. Bu bağlamda, Doğu-Batı tasvir sanatı etkileșimi adına önemlidir.

${ }^{13}$ Vat. gr. 755'de, Kitab-1 Mukaddes'ten Yeșeya'nın Kitabı'nın bir bölümü ve Krallar Kitabı yer alır.

14 Takiguchi, Mika, "The Prophet Book", A Companion to Byzantine Illustrated Manuscripts, (Ed. Vasiliki Tsamakda), Brill, Leiden-Boston, 2017. s. 248. 
isimlerden dördünün de Yeşeya peygamber ile ilgili söylemleri olduğu bilinmektedir. Özellikle Yeşeya peygamberin, İsa ile ilgili kehanetleri konusunda Kyrrhuslu Theodoretos'un önemli bir yeri olduğu söylenebilir.

Bu grup için seçilen bir diğer örnek; 14. yüzy1l Paris. gr. 1128'de yer alır. Paris. gr. 1128 fol. 50r.'de, Yeşeya peygamber yüzünü Aziz Pavlus'a dönmüş ve eliyle de ona rehberlik ederken tasvir edilmiştir. Gerek Yeşeya peygamber ve gerekse Aziz Pavlus'un üzerlerindeki kıyafetlerin çeşidi ve rengi birebir aynı şekilde resmedilmiştir. (Resim 3)

Yeşeya peygamberin kutsal isimler ile birlikte yer aldığ örnekleri arasında, Kitab-1 Mukaddes temalı sahneler de vardır. Sacra Parallela/Paris. gr. 923, fol. 16v.'de sahneler soldan sağa; "Yakup, Yusuf'un Ölüm Haberini Alırken-Yeşeya Peygamber-Yakup 'un Ağıtı' sahneleri şeklindedir. Sahnede, Yeşeya bir büst portre ile Yakup'un, Yusuf'un Ölüm Haberini Alırken ve Yakup'un Ağıtı sahneleri arasında yer alır. Tasvirde; Yeşeya'nın bakışları Yusuf'un kardeşlerine doğru yönelmiştir ${ }^{15}$. Bu bağlamda, Yusuf'un kardeşlerinin yaptıklarını tasvip etmeme durumu söz konusudur. (Resim 4).

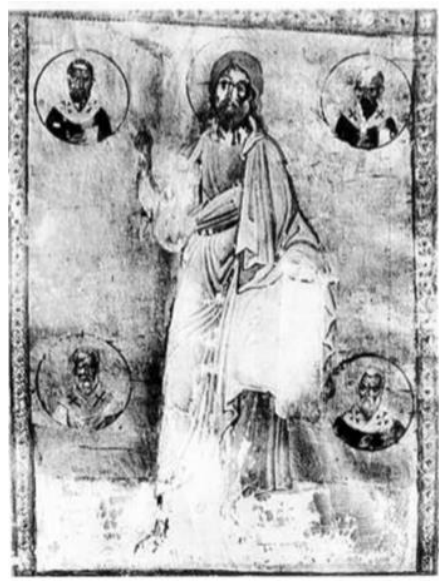

Resim 2: Yeşeya Peygamber ve Dört Kilise Babası (Kaisarealı Basileos, Kyrrhuslu Theodoretos, İskenderiyeli Krill/Kyrillos, Heraklial1 Theodoretos), Vat. gr. 755 fol. 1r. Vatikan Apostolik Kütüphanesi, (Bernabò 1995, fig. 2, s. 80)

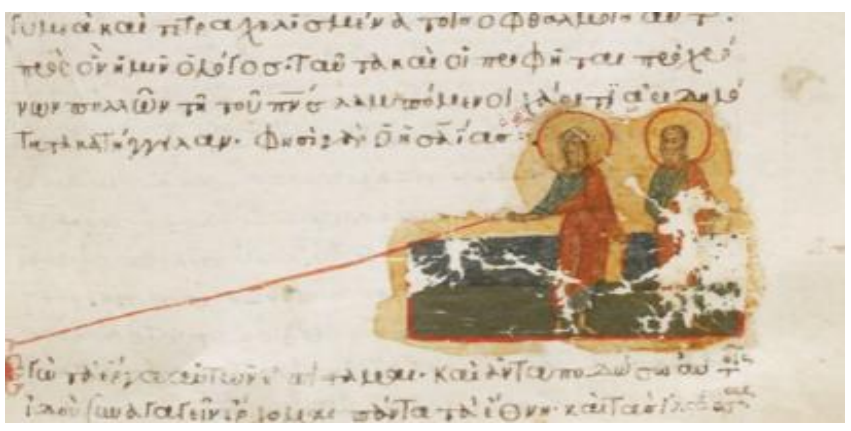

Resim 3: Yeşeya Peygamber ve Aziz Pavlus, Par. gr. 1128 fol. 50r., Fransa Millî Kütüphanesi ( ${ }^{\circledR}$ Gallica.bnf.fr) https://gallica.bnf.fr/ark:/12148/btv1b8452659r/f146.item.zoom

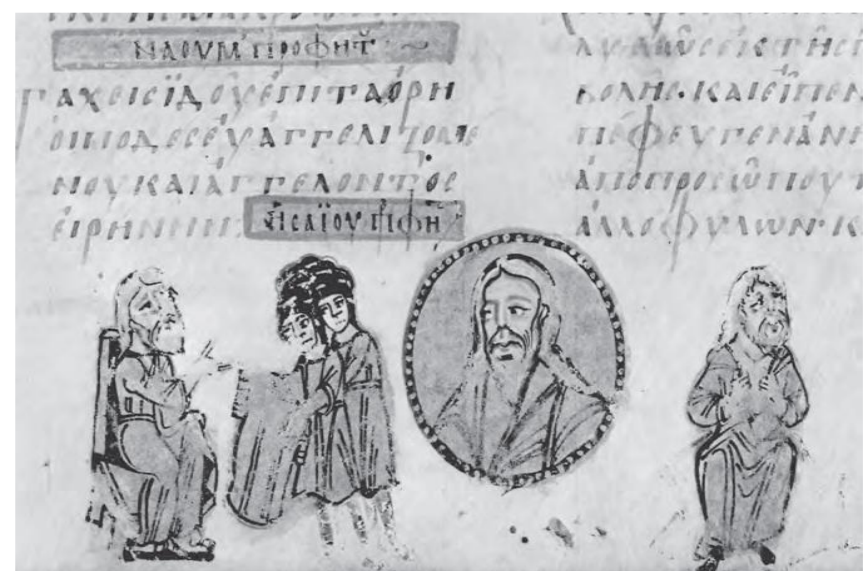

Resim 4: Yakup, Yusuf'un Ölüm Haberini Alırken-Yeşeya Peygamber-Yakup'un Ağıtı (Soldan Sağa), Sacra Parallela/Paris. gr. 923, fol. 16v., Fransa Millî Kütüphanesi ( ${ }^{\circ}$ Gallica.bnf.fr), (Evangelatou, 2017, s. 194, fig. 72) ${ }^{16}$

$\mathrm{Bu}$ grup için seçilen son örnek; 10. yüzyıla tarihlenen Trabzon Leksionarianu ya da Cod. gr. 21, fol. 11v.'dir. Bu örneklendirme; Yakup, Yusuf'un Ölüm Haberini Alırken-Yeşeya-PeygamberYakup'un Ăgıtı sahnesi örneğinden biraz daha farklı bir ikonografi içerir. Bu bağlamda, Yeșeya peygamberin, kutsal isimler ile birlikte yer aldığ sahnelerin bazılarında, Cod. gr. 21 fol. 11v.'de; İsa, Yeșeya Peygamberin Kehanetini Okurken sahnesinde olduğu gibi tasviri değil, sadece adı geçmektedir ${ }^{17}$. Kyrrhuslu Theodoretos'un de belirttiği üzere, Yeşeya peygamber en çok İsa ile ilgili kehanetleri ile bilinmektedir. Bu bağlamda; İsa, Yeșeya Peygamberin Kehanetini Okurken sahnesi, Eski Ahit odaklı Yeşeya kehanetlerine gönderme yapması adına da dikkate değerdir. (Resim 5).

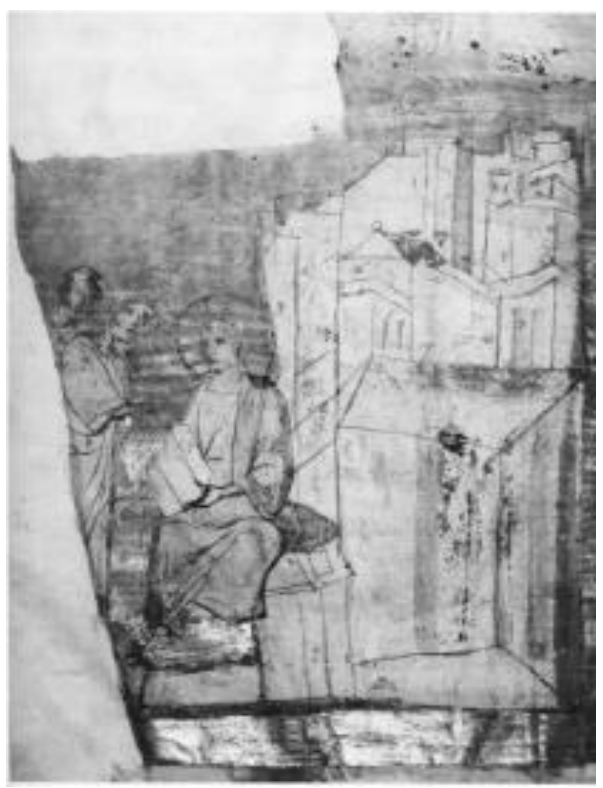

Resim 5: İsa, Yeşeya Peygamberin Kehanetlerini Okurken Sahnesi, Trabzon Leksionarianu Cod. gr. 21, fol. 11v., St. Petersburg Rusya Milli Kütüphanesi, $\left({ }^{\circ}\right.$ nlr.ru/eng), (Zakharova, 1995, Fig. 13)
15 Resmin yanında yer alan metinde, Yeşeya 52:7'ye istinaden bazı açıklamalar vardır. Yeşeya'nın büst portresinin hemen sol üstündeki ifadede;

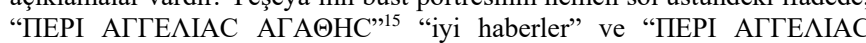
KAKHC" "Kötü Haberler" ifadesi ile Kitab-1 Mukaddes Yaratılıș 37:31-34 arasında bağlantı vardır. Geniş bilgi için bk. Evangelatou, "Word and...", s. 191 ve dipnot 348-349.

16 Görsel için ayrıca bk.

https://gallica.bnf.fr/ark:/12148/btv1b525013124/f36.item

${ }^{17}$ Cod. gr. 21 ve fol. 11v. geniş bilgi için bk. Zakharova, 1995, Fig. 13. 


\subsection{Yeşeya Peygamberin Duası/Ílahisi/Şarkısı/Rüyası}

Yeşeya Peygamberin, Kitab-1 Mukaddes referanslı olarak en bilindik sahnesi; Yeşeya'nın Duası/İlahisi/Şarkısı/Rüyası gibi isimlerle anılır. Sahnenin kendi içinde ikonografik bir bütünlük içermediği ve farkl ikonografik detaylara sahip olduğu gözlemlenir.

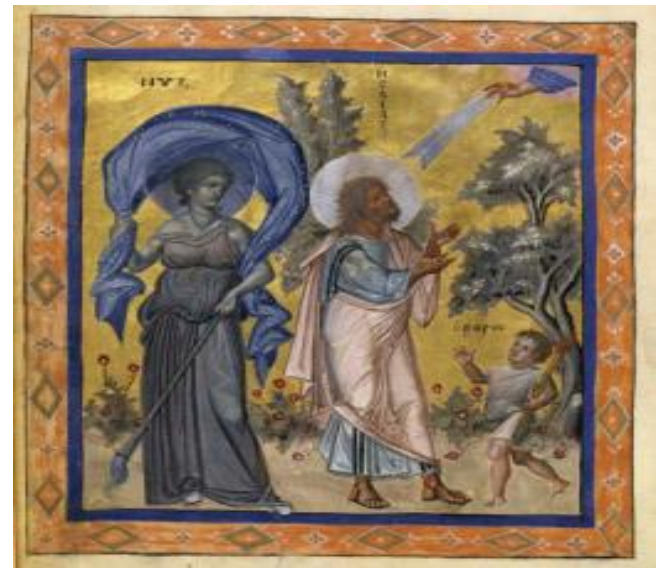

Resim 6: Yeşeya Peygamberin Duas1/Ilahisi/Şarkısı, Paris Psalter/Paris. gr. 139, fol. 435v., Fransa Millî Kütüphanesi ( ${ }^{\circ}$ Gallica.bnf.fr), (Dipippo, 2017) ${ }^{18}$

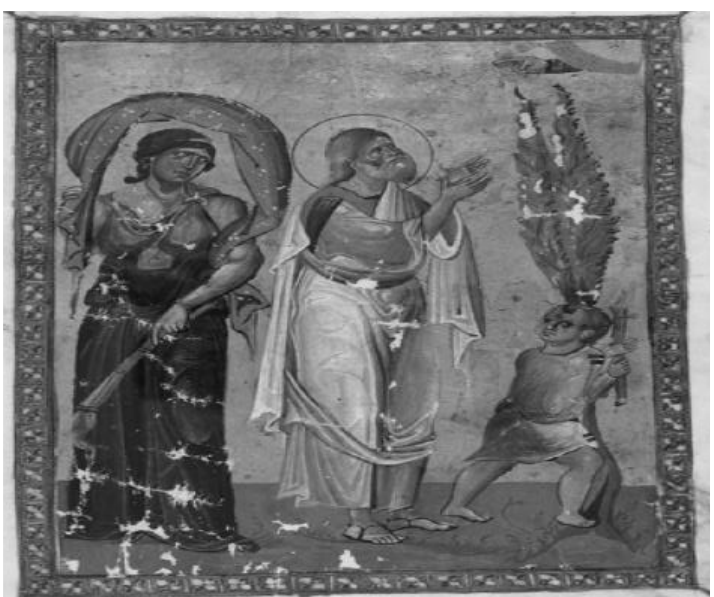

Resim 7: Yeşeya Peygamberin Duası/İlahisi/Şarkıs1, Vat. gr. 755, fol. 107r., Vatikan Apostolik Kütüphanesi, $\left({ }^{\circ}\right.$ digi.vatlib.it), ((Takiguchi, 2017, fig. 85)

18 Görsel için ayrıca

https://gallica.bnf.fr/ark:/12148/btv1b10515446x/f894.item.zoom Görsel için

${ }^{20}$ Geniş bilgi için bk. Dufrenne, Suzy; "Problèmes des ateliers de miniaturistes byzantins", Jahrbuch der Österreichischen Byzantinistik, $31 / 2$ (1981), ss. 453 $454,461$.

${ }^{21}$ Görsel için bk. https://www.doaks.org/resources/manuscripts-in-thebyzantine-collection/psalter-and-new-testament

${ }^{22}$ Kişiselleştirilmiş gece ve şafak tasvirleri geniş bilgi için bk. Kaya, İlkgül; "Paris Psalterionu (Cod. gr. 139, Paris-Ulusal Kütüphanesi) ve Makedonya Rönesansı". (ed.) Ceken, M. - Giray, K.- Giray, M. - Sunay. S. Sanat ve Estetikte Asal Değerler Mekan Zaman, 2015, Ankara, 2015, s. 222.

${ }^{23}$ Geniş bilgi için bk. Takiguchi, "The Prophet..." s. 256-257.

${ }^{24}$ Seraph'ın çoğul hali olarak kullanılmıștır.

${ }^{25}$ Geniş bilgi için bk. Brubaker, Leslie, "The Homilies of Gregory of Nazianzus", A Companion to Byzantine Illustrated Manuscripts, (Ed. Vasiliki Tsamakda), Brill, Leiden-Boston, 2017, s. 362.
Bunlardan çalıșma kapsamında ele alınan ilk grup; Yeşeya 26:9'u; "Geceleri canım sana susar, evet, içimde ruhum seni özler; çünkü senin ilkelerin yeryüzünde oldukça, orada oturanlar doğruluğu ögrenir." referans alır. Paris Psalter/Paris. gr. 139, fol. 435v. (10. yüzyıl), Psalterium et cantica/Supp. Paris gr. 610, fol. 256v. (11. yüzy11) ${ }^{19}$, Vat. gr. $755^{20}$, fol. 107r. (11. yüzy1l) (Resim 7), Dumbarton Oaks MS. 3, BZ. 1962.35, fol. 77 (11. yüzyıl) $)^{21}$ örneklerinde ikonografi hemen hemen aynıdır. Yeșeya peygamber; dağlık açık bir alanda, elinde meşale ile şafağı temsil eden küçük bir çocuğun rehberliğinde ilerlerken, gece ise genelde bir kadın figürü ile kişiselleştirilmiş şekilde sahneye yerleștirilmiștir ${ }^{22}$. Sahnenin sağ üst köşesinde, resme diyagonal yerleştirilmiş Tanrı'nın eli ve ş̧ı̆̆ tüm örneklerde yerini alır. Ancak Paris Psalter örneğinde, dağlık bir alandan çok ormanlık bir alan izlenimi gözlemlenir (Resim 6).

Kitab-1 Mukaddes Yeşeya Sevinç İlahisi/26: 7'de; "Doğru adamın yolu düzdür, Ey Dürüst olan, doğru adamın yolunu sen düzlersin." ve Yeşeya Avutucu Sözler/40: 3-4'de; "Şöyle haykırlyor bir ses: Çölde Rabb'in yolunu hazırlayın, bozkırda Tanrımız için düz bir yol açın. Her vadi yükseltilecek, her dăg, her tepe alçaltılacak. Böylelikle engebeler düzleștirilecek, sarp yerler ovaya dönüșürülecek." ifadelerinin Şafak/O $\rho \theta \rho o s / O r t h r o s$ ikonografisi üzerinde etkili olduğunu düşünen araştırmacılar mevcuttur. Orthos/O $\rho \theta$ ó kelimesinin Yunanca "doğru/düz/güvenilir" anlamı mevcuttur. Bu bağlamda, yukarıdaki Yeşeya Kitabı alıntıları ile ilintili olarak, Şafak ile ses benzerliği olan "doğru" ifadesi ortak bir temada buluşur. Böylece kişiselleştirilmiş şafak, Yeşeya Peygamberin ruhuna doğru yolda rehberlik yapmaktadir ${ }^{23}$.

İkinci grup örnekte sahne; Yeşeya Kitabı Rab Yeşeya'yı Çağırıyor bölümü 6: 1-3'ü referans alır. "Uzziya'nın öldügü yıl yüce ve görkemli Rab'bi gördüm; tahtta oturuyordu, giysisinin etekleri tapinağ dolduruyordu. Üzerinde Seraphlar duruyordu; her birinin altı kanadı vardı: ikisiyle yüzlerini, ikisiyle ayaklarını örtüyor, öbür ikisiyle de uçuyorlardı... Seraphların sesinden kapı söveleriyle eşikler sarsıldı, tapınak dumanla doldu.". Sahnedeki ikonografiye göre, tasvirin üst bölümünde tahtta oturan Rabb'e seraphim ${ }^{24}$ eşlik etmektedir ve sahnenin alt düzleminde (sağ ya da sol) ona ellerini açmış dua eden Yeşeya peygamber tasviri yer alır. Bu gruba verilen örnekler; Sacra Parallela/Paris. gr. 923, fol. 39v. (9. yüzyıl) (Resim 8) Naziansoslu Gregorios'un Homiliyeleri/Paris. gr. 510, fol. 67v. (9. yüzyıl) ${ }^{25}$ (Resim 9), Cosmas Indicopleustes/Vat. gr. $699^{26}$ fol. $72 \mathrm{v}$.'de (9. yüzyıl) (Resim 10) Yeşeya Peygamberin Rüyası sahnesi ${ }^{27}$ şeklindedir. Resimdeki tasvirde; kompozisyonun sol veya sağ düzlemlerine yerleştirilmiş Yeşeya peygamber, diz çökmüş ve dua eder vaziyettedir. Resmin üst merkez düzlemine ise tahtında oturan Rab yerleştirilmiştir. Seraphim ise kutsal metne sadık kalınarak uçuşur vaziyette resmedilmiştir.

Sacra Parallela/Paris. gr. 923, fol. 39v.'deki Yeşeya Peygamberin Rüyası sahnesi, bu gruplama içerisinde farklı bir ayrıntı içerir. Sol marja yerleştirilmiş sahnede; İsa, altı kanatlı bir seraphın desteklediği tahtında oturmaktadır. Yeşeya ise hemen altında ellerini ve başını

26 6. yüzyılda yaşamış Cosmas Indicopleustes'un Topographie Chrétienne/Hiristiyan Topografyası resimli el yazması, dinî odaklı bir el yazması değildir. Ağırlıklı olarak kartografya ve coğrafya bilgiler içeren el yazmasının 6. yüzyıl örneği günümüze gelememiştir. Ancak farklı tarihlerde yazılmıș üç kopyası mevcuttur. 9. yüzyıla tarihlenen Vat. gr. 699 Roma Vatikan Apostolik Kütüphanesi'nde, 11. yüzylla tarihlenen Cod. gr. 1186 Sina Azize Katerina Manastırı Kütüphanesi'nde ve Plut. 9.28 ise Floransa Laurenziana Kütüphanesi'nde muhafaza edilmektedir. Bunlara ek olarak birkaç yaprak halinde muhafaza edilen bir diğer kopya ise Viyana Kraliyet Kütüphanesi'nde korunmaktadır.

${ }^{27}$ Sahnede, İsa'nın Günlerin Eskisi olarak tasvir edilmesi geniş bilgi için bk. Zenbilci, Kaya, İlkgül; "Bizans Sanatında Nadir Bir İsa Tiplemesi: Günlerin Eskisi (Ho Palaios Ton Hemeron)". (ed.) Faozi F.-Sinanoğlu A. Biltek Uluslararast Bilim, Teknoloji ve Sosyal Bilimlerde Güncel Gelișmeler Seтроzуити, 2019, Ankara, 2019. ss. 20-42. 
İsa'ya doğru kaldırıp dua ederken tasvir edilmiştir. Sahne, sol marja yerleştirilmiş olması adına diğer iki örnekten ayrılır. (Resim 8).

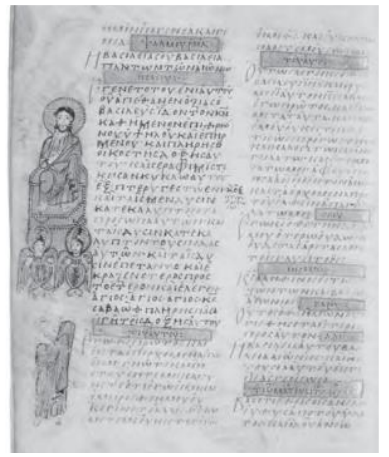

Resim 8: Yeşeya'nın Rüyası, Sacra Parallela/Paris. gr. 923, fol. 39v., Fransa Millî Kütüphanesi ( ${ }^{\circ}$ Gallica.bnf.fr), (Evangelatou, 2017, s.195, fig. 73).

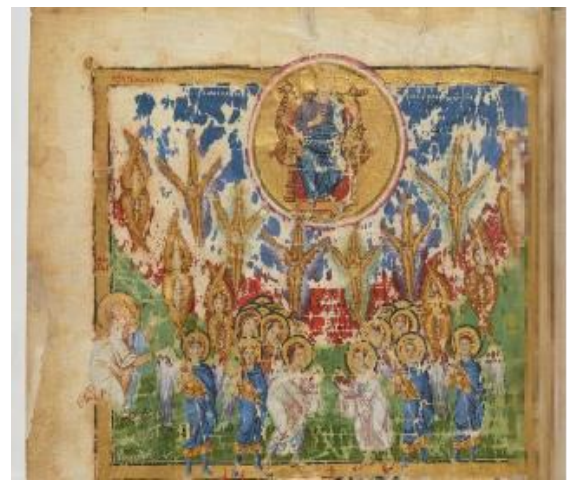

Resim 9: Yeşeya'nın Rüyası, Naziansoslu Gregorios'un Homiliyeleri/Paris. gr. 510, fol. 67v. Fransa Millî Kütüphanesi $\left({ }^{\mathbb{C}} \text { Gallica.bnf.fr }\right)^{28}$

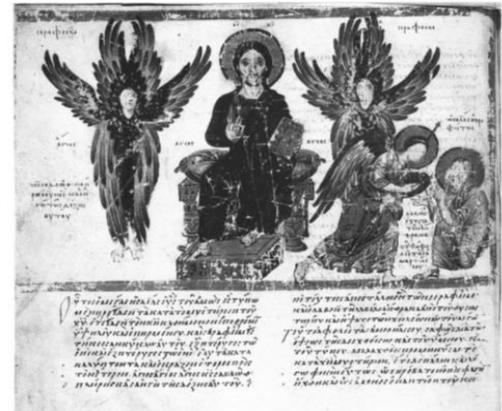

Resim 10: Yeşeya'nın Rüyası, Cosmas Indicopleustes/Vat. gr. 699, fol. 72v., Vatikan Apostolik Kütüphanesi, $\left({ }^{\circ}\right.$ digi.vatlib.it), (Brubaker, 2008, s. 117, fig. 76)

Üçüncü bir alt gruba dâhil edebileceğimiz Theodoros Psalter Add. MS. 19352 fol. 199v. (11. yüzyıl) (Resim 11) ve Kiev/Spiridon Psalter (1397) (Resim 12) örnekleri; yukarıda verilen iki kutsal metin Yeşeya 6: 1-3 ve 26: 9'a aynı anda göndermede bulunur. Theodoros ve Kiev örneklerinde; elinde meşale ile kişiselleştirilmiş şafak tasviri yer alır. Theodoros Psalter'da ayrıca Yeşeya Kitabı 6:1-3'e referans olarak madalyon içerisinde İsa, tahtında oturmaktadır. Diğer
$28 \quad$ Görsel için

https://gallica.bnf.fr/ark:/12148/btv1b84522082/f148.item.zoom

${ }^{29}$ Cvetković, Branislav; "Vision of the Heavenly City in Jošanica Monastery", IKON, 6 (2013), 9.

${ }^{30}$ Meyer; makalesinde, Sion şehrinin kişiselleştirilme örnekleri üzerinden değerlendirme yapar. Verdiği bazı örneklerde, büyük bir yapı Sion'u temsil etmektedir. Geniş bilgi için bk. Meyer, Mati; “The Personification of Zion in taraftaniev Psalter örneğindeki çelengin, tahtı sembolize ettiği de söylenebilir. Cvetković29; Kiev Psalter örneğindeki büyük binanın, Sion olabileceğini Meyer'in ${ }^{30}$ makalesine atıf vererek iddia eder. $\mathrm{Bu}$ bağlamda; sahnede yer alan büyük binanın ikonografisinin Psalm 69: 35-36; “Tanrı, Sion'u kurtaracak ve Yahuda şehrini yeniden kuracak ve insanlar oraya yeniden yerleşecek" ifadesinden etkilenmiş olma ihtimali yüksektir.

Diğer taraftan Theodoros ve Kiev Psalter örneklerindeki kişiselleştirilmiş Şafak tasvirine yapılan vurgu, yukarıda resim 6 ve 7'deki örnekler için belirtmiş olduğumuz gibi Şafak/O $\rho \theta \rho \circ$ /Orthros'un, Yunanca "doğru/düz/güvenilir" anlamına

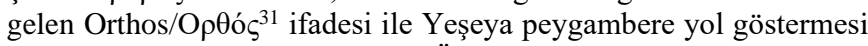
adına da ayrı bir öneme sahiptir. Örneklerden Theodoros Psalter'da elinde meşale ile Şafak İsa'ya doğru rehberlik yaparken, Kiev Psalter örneğinde ise elinde meşale ile Şafak büyük bir binayı göstererek ve yine sembolik olarak Psalm 69: 35-36'ya atıfta bulunarak, Sion'un kurtuluşuna ve yeniden kurulacak olan Yahuda şehrine göndermede bulunur.

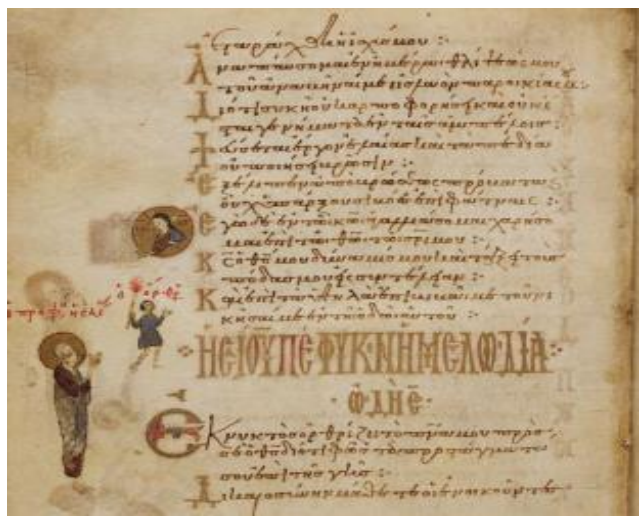

Resim 11: Yeşeya Peygamberin İlahisi/Duası, Theodoros Psalter Add. MS. 19352, fol. 199v. $\left({ }^{\circ} \text { British Library }\right)^{32}$

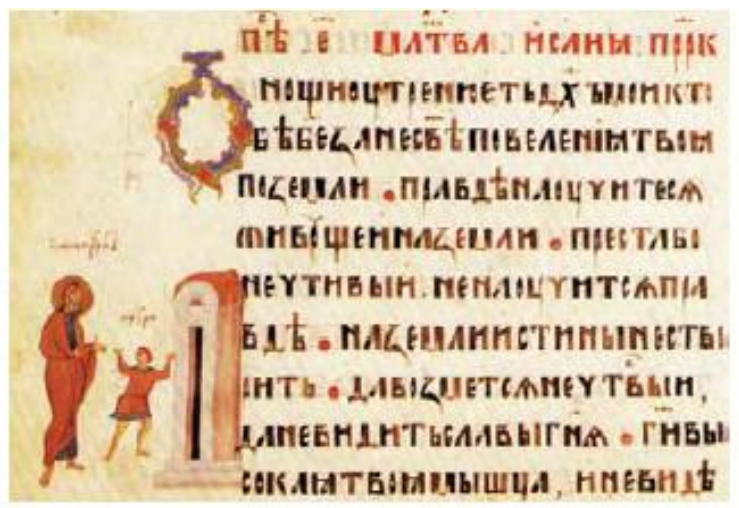

Resim 12: Yeşeya Peygamberin İlahisi/Duası, Kiev/Spiridon Psalter $\left({ }^{\circ}\right.$ Rusya Boris Yeltsin Başkanlık Kütüphanesi), (Cvetković, 2013, s. 9 , fig. 13$)^{33}$

Byzantine Psalters with Marginal Illustrations: Between Eschatological Hopes and Realia", Ars Iudaica, 7, Bar-Illan University, 2009, 7-22, fig. 1-3, 10.

${ }^{31}$ İki kelimenin etimolojik kökeni geniş bilgi için bk. Frisk, Hjalmar; Griechisches Etymologisches Worterbuch, 3 vols., Heidelberg, 1969-72, 416.

http://www.bl.uk/manuscripts/Viewer.aspx?ref=add_ms_19352_f192v

${ }^{33}$ Görsel için bk. https://www.prlib.ru/en/node/465928 


\subsection{Hezekiel’in Hastalığı/İyileşmesi ve Yeşeya Peygamber}

Yeşeya Peygamberin tasvirini Hezekiel'in Hastalığı ve İyileşmesi sahnelerinde görmek mümkündür. Sahnenin ikonografisi, Yeşaya Kitab1 Hezekiel'in Hastalı̆̆ $138: 1-8$; “O günlerde Hezekiel ölümcül bir hastalığa yakalandı. Amots oğlu Peygamber Yeşeya ona gidip söyle dedi; 'Rab diyor $k i$, 'Ev islerini düzene sok. Ç̈̈nkü iyileşmeyecek öleceksin.' Hezekiel yüzünü duvara dönüp Rab'be yalvardl. 'Ya Rab, yürekten bir sadakatle önünde nasıl yașadığımı, gözünde iyi olanı yaptığımı anımsa lütfen.' Sonra acı ile ă̆lamaya başladı. Bunun üzerine Rab Yeșeya'ya seslendi. 'Git, Hezekiel'e șunu söyle; 'Atan Davud'un Tanrıs'sı Rab diyor ki: Duanı işittim, gözyaşlarını gördüm. Bak ömrünü on beş yıl daha uzatacağım. Bu kenti savunacak, seni de kenti de Asur Kralı'nın elinden kurtaracağım. Sözümü gerçekleştireceğime ilişkin sana vereceğim belirti su olacak: Rab, batmakta olan güneșin Ahaz'in inșa ettiğ basamakların üzerine düşen gölgesini on basamak kisaltacak. Böylece batmakta olan güneşin gölgesi on basamak kısaldı. " referans alır.

Sahneyi; Sacra Parallela/Paris. gr. 923, fol. 252v. (9. yüzyıl) (Resim 13), Naziansoslu Gregorios'un Homiliyeleri/Paris. gr. 510 , fol. $435 \mathrm{v}$ (9. yüzyıl) (Resim 14), ve Paris Psalter/Paris. gr. 139, fol. 446v.'de (10 yüzyıl) (Resim 15) görmek mümkündür. Sahnenin ikonografisine göre; Hezekiel hasta yatağında yatmakta ve Yeşeya Peygamber, onunla Tanrı arasında aracılık yapmaktadır. Sahnenin üç örneğinde de Hezekiel üzüntülü bir biçimde yüzünü kutsal metne bağlı kalarak duvara dönmüş vaziyettedir. Tasvirlerdeki merdivenin ikonografik yorumlamaları da farklıdır. Paris. gr. 510 ve Paris. gr. 139 örneklerinde, Hezekiel'in hasta yatağı, açık alanda evlerin önündedir. Bu bağlamda yine kutsal metinde belirtildiği üzere, babası Ahaz'ın (evindeki) merdiveni, bu iki örnekte "ev işlerini düzene koy" ifadesi gereğince atası Ahaz'ın evi ile birlikte verilmiştir. Resimdeki merdiven ise, Tanrı'nın Hezekiel'e söz verdiği üzere güneş hareketi ile aşağı yukarı hareket eden güneş 1şığ ile ona bir işaret göndermesine delildir ${ }^{34}$.

Sahnenin en önemli ikonografik elemanı olan merdiven için araştırmacıların farklı görüşleri vardır. Weitzmann ${ }^{35}$; tasviri yapan kişinin modellemeyi yanlış anladığını, Yeşeya 38:8'e göre 10 basamaklı bir güneș saati olması gerekirken, daha fazla basamaklı bir merdiven yaptığına değinir. Evangelatou'ya ${ }^{36}$ göre ise; Septuagint'te bahsi geçtiği üzere Hezekiel'in baba evinde, güneş saati değil, bir merdiven vardır. Buna göre, güneş 1şı̆̆ının bu merdivende 10 basamak inip çıkacağına dair bir referans vardır. Fakat bu ifadenin, merdivenin 10 basamaktan ibaret olması gerekliliği anlamı taşımadığını belirtir. Sahnedeki merdivenin neden 15 basamaktan ibaret olmasına ise bir açıklama getirir. Kutsal metin referanslı olarak, 15 basamaklı merdivenin, Tanrı'nın Hezekiel'e söz verdiği gibi $15 \mathrm{y1}$ ömrünü uzatacağına dair vermiş olduğu sözüne bir atıf niteliği taşımaktadır.

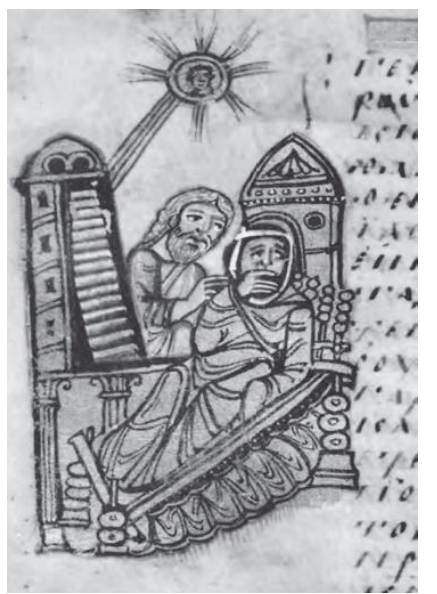

Resim 13: Hezekiel'in Hastalı̆̆g/İyileşmesi ve Yeşeya Peygamber, Sacra Parallela/Paris. gr. 923, fol. 252v., Paris Milli Kütüphanesi, ( ${ }^{\circ}$ Gallica.bnf.fr), (Evangelatou, 2017, s. 168, Fig. 42)

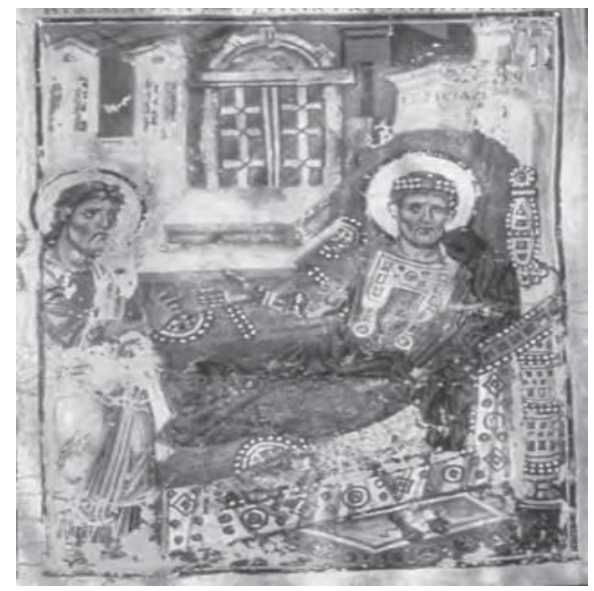

Resim 14: Hezekiel'in Hastalı̆̆g/İyileşmesi ve Yeşeya Peygamber, Naziansoslu Gregorios'un Homiliyeleri/Paris. gr. 510, fol. 435v., Paris Milli Kütüphanesi, ( ${ }^{\odot}$ Gallica.bnf.fr), (Evangelatou, 2017, s. 168, Fig. 43)

\footnotetext{
${ }^{34}$ Merdiven detayı geniş bilgi için bk. Evangelatou, Maria; "Word and Image in the Sacra Parallela (Codex Parisinus Graecus 923)", Dumbarton Oaks Papers, Number Sixty-Two, 2009, (Ed. Alice-Mary Talbot), Dumbarton Oaks Research Library and Collection: Washington D.C., 2009, s. 166-167.
}

${ }^{35}$ Weitzmann, Kurt, The Miniatures of the Sacra Parallela, Parisinus Graecus 923 (Studies in Manuscript Illumination, 8), Princeton University Press, Princeton, 1979. ss. 147-18.

${ }^{36}$ Evangelatou, "Word and...", s. 169, dipnotlar; 253-254. 


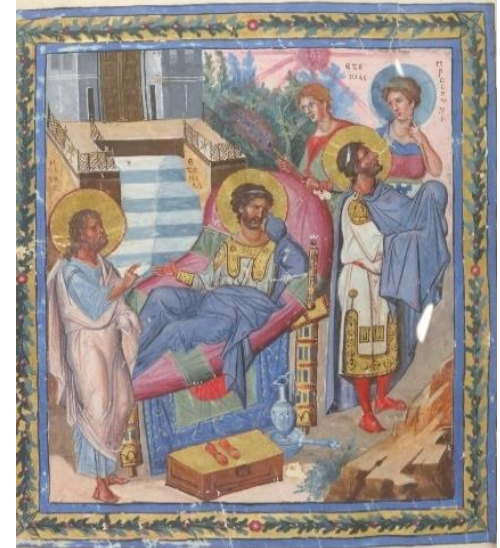

Resim 15: Hezekiel'in Hastalı̆̆//Iyileşmesi ve Yeşeya Peygamber, Paris Psalter/Paris. gr. 139, fol. 446v., Paris Milli Kütüphanesi, $\left({ }^{\circ}\right.$ Gallica.bnf.fr), (Dipippo, 2017)

\subsection{Yeşeya Peygamberin Şehit Edilmesi}

Çalışma kapsamında son grupta Yeşeya Peygamberin Şehit Edilmesi sahnesi ele alınmıştır. Yeşeya peygamberin şehit edilişsi ${ }^{37}, 2$. yüzyıla tarihlenen farklı metinlerin (Etiyopya Dili/Amharca, Yeni Yunanca, Slavca ve Latince) çevirilerinden oluşan Yeşeya'nın Göğe Yükselişi eserinde geçen pseudoepigrapha/psödipigrafa kökenli bir Hıristiyanİbrani efsanesidir ${ }^{38}$. Eserin 5. bölümünde; şeytan Beliar'ın etkisiyle sahte peygamber Belkira, kral Manaşşe'yi, Yeşeya'nın bir hain olduğu noktasında ikna etmiş ve kışkırtmıştır. Sonuç olarak; Kral Manaşşe'nin kararı ve emri ile Yeşeya peygamber ahşaptan bir testere ile şehit edilmiştir ${ }^{39}$.

Naziansoslu Gregorios'un Homiliyeleri/Paris. gr. 510 fol. 347v. (9. yüzy1l) (Resim 16) ve Vat. gr. 755 gr. fol. 225r. (11. yüzy1l) (Resim 17) örneklerinde, Yeşeya yere diz çökmüş vaziyettedir ve iki kişi testere ile Yeşeya'nın bedenini ikiye ayırarak şehit ederken tasvir edilmişlerdir ${ }^{40}$.

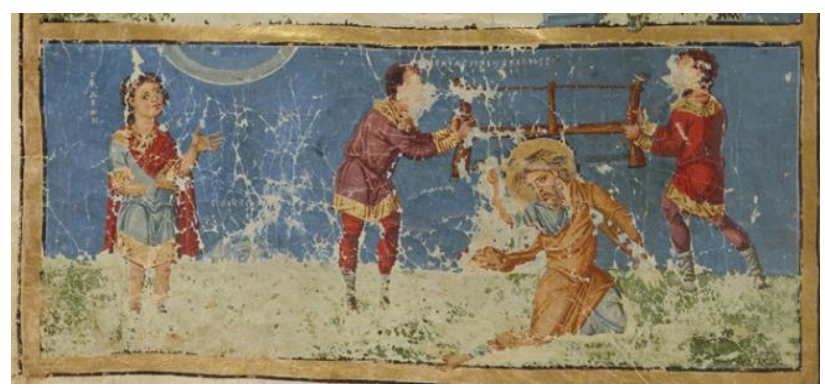

Resim 16: Yeşeya Peygamberin Şehit Edilişi, Naziansoslu Gregorios'un Homiliyeleri/Paris BnF Ms. gr. 510, fol. 347v., $\left({ }^{\circ}\right.$ Gallica.bnf.fr)

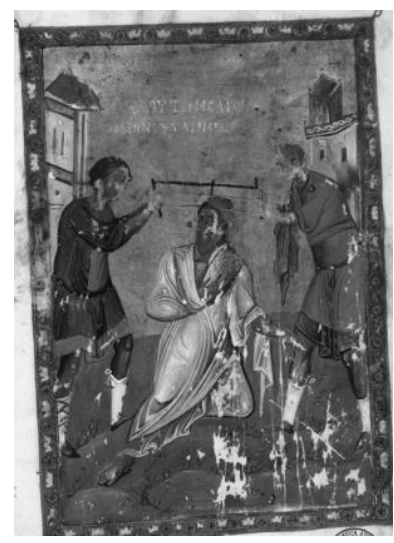

Resim 17: Yeşeya Peygamberin Şehit Edilişi, Vatikan Apostolik Kütüphanesi, Vat. gr. 755, fol. 225r., (Takiguchi, fig. 87)

\section{Sonuç}

MÖ. 8. yüzyılda yaşamış olan ve Kitab-1 Mukaddes'in dört büyük peygamberinden birisi kabul edilen Yeşeya peygamberin Bizans tasvir sanatındaki yeri yadsınamayacak derecede önemlidir. Tasvir sanatının hemen hemen her alanında karşımıza çıkan Yeşeya peygamber tasvirleri, en çok Psalter ve Peygamber Kitabı gibi çeşitli dinî el yazmalarında yer alır. Tasvirlerde Yeşaya peygamber genelde uzun beyaz saçlı ve sakallı olarak betimlenmiştir. Peygamberlerin önemli bir atribüsü olarak elinde genelde çeşitli kutsal metinlerin yazılı olduğu açık bir rulo vardır.

Çalışma kapsamında Yeşeya peygamberin tasvirleri çeşitli gruplamalar yapılarak incelenmiştir. Tam sayfa tek başına olan tasvirlerinin yanı sıra, diğer kutsal isimler ile birlikte de portre tasvirleri mevcuttur. Kitab-1 Mukaddes temalı sahnelerde, Yeşeya peygamberin en çok kehanetleri karşımıza çıkar. İlahisi, duası ya da rüyası olarak da bilinen bu sahnelerde, kişiselleştirilmiş şafak ve gece tasvirlerinin yer alması ve bu ikonografinin farklı detaylar ile geliştirilerek yorumlaması önemlidir. Fakat, Yeşeya Peygamberin şehit edilmesi, Kitab-1 Mukaddes kaynaklı değildir. Pseudepigrapha kökenli bir Hıristiyan-İbrani efsanesi etkili bir sahnenin, dinî el yazmaları resimlerinde yer alması adına da dikkate değerdir.
${ }^{37}$ Yeşeya'nın şehit edilişi ile ilgili ilk ip uçlarını Kitab-ı Mukaddes 2. Krallar 21 'de görmek mümkündür. Buna göre Hezekiel'den sonra başa geçecek oğlu Manaşşe babasının yolunu takip etmeyecek ve putlara olan inancı desteleyecektir.

${ }_{38}$ Charles, R. H. tarafindan derlenen, Etiyopya, Yeni Yunanca, Latince ve Slavca metinleri olan Yeşeya'nın Göğe Yükselişi kitabı üç bölüme ayrılır (Yeşeya'nın Şehit Edilişi, Yeşeya'nın Rüyası ve Hezekiel'in Ahiti). Geniş bilgi için bk. R. H. Charles; Ascension of Isaiah, Adam and Charles Black, London, 1900. Ayrica bk. Bernheimer, Richard; "The Martyrdom of Isaiah", The Art Bulletin, 34(1), (1952), ss. 19-34, Ziegler, Joseph; Untersuchungen zur Septuaginta des Buches Isaias, ATA XII, 3; Münster: Aschendorff, 1934 Van der Vorm-Croughsi Mirjam; "The Old Greek of Isaiah An Analysis of Its Pluses and Minuses", The Old Greek of Isaiah, Vol. 61, Septuagint and
Cognate Studies,2014, (Ed. Wolfgang Kraus), Society of Biblical Literature: Atlanta.

${ }^{39}$ Geniş bilgi için bk. R. H. Charles; Ascension of Isaiah, Adam and Charles Black, London, 1900, ss. 40-42.

${ }^{40}$ Lowden, Paris. gr. 510'daki Yeşeya kitap resmi örneklerinin birbirleri üzerindeki etkileri üzerinde durur. Yeşaya Peygamberin Şehit Edilmesi sahnesi üzerinden yola çıkarak Paris. gr. 510'daki sahnenin, Vat. gr. 755'deki sahne üzerinde direkt olarak etkili olmadığı ancak genel itibariyle Paris. gr. 139 örneğinin etkili olma ihtimali üzerinde durur. Geniş bilgi için bk. Lowden, John; Illuminated Prophet Books: A Study of Byzantine Manuscripts of the Major and Minor Prophets, Penn State University Press, Pennsylvania, 1990. ss. 67-69.ê 


\section{KAYNAKÇA}

Bernabò, Massimo; "Lo studio della illustrazione dei manoscritti greci del Vecchio Testamento: ca. 1820-1990," Medioevo e Rinascimento 9 , n.s. 6 (1995), ss. 261-99.

Bernheimer, Richard; “The Martyrdom of Isaiah”, The Art Bulletin, 34(1), (1952), ss. 19-34.

Brubaker, Leslie; Vision and Meaning in Ninth-Century Byzantium. Images as Exegesis in the Homilies of Gregory of Naziansus, Cambridge: Cambridge University Press. 2008.

Brubaker, Leslie; “The Homilies of Gregory of Nazianzus”, A Companion to Byzantine Illustrated Manuscripts, (Ed. Vasiliki Tsamakda), Brill, Leiden-Boston, 2017, ss. 351-365.

Cvetković, Branislav; "Vision of the Heavenly City in Jošanica Monastery”, IKON, 6 (2013), ss. 1-16.

Dufrenne, Suzy; "Problèmes des ateliers de miniaturistes byzantins", Jahrbuch der Österreichischen Byzantinistik, 31/2 (1981), ss. 445-470.

Dinçer, Serdar Pınar; “El Yazmasının Kökeni ve Terminoloji Önerileri”, İdil, 5(23), (2016), ss. 931-940.

Dipippo, Gregory; "The Paris Psalter”, New Liturgical Movement Sacred Liturgy \& Liturgical Arts, $2017 . \quad$ URL: http://www.newliturgicalmovement.org/2017/02/the-paris-psalter.html\#.X6JosYgzbIU

Earle, Ralph; Meet the Major Prophets, Beacon Hill Press, Kansas City, 1958.

Evangelatou, Maria; "Word and Image in the Sacra Parallela (Codex Parisinus Graecus 923)", Dumbarton Oaks Papers, Number Sixty-Two, 2009, (ed. Alice-Mary Talbot), Dumbarton Oaks Research Library and Collection: Washington D.C., 2009, 113-198.

Evangelatou, Maria, "Sacra Parallela (*Par. gr. 923)", A Companion to Byzantine Illustrated Manuscripts, (Ed. Vasiliki Tsamakda), Brill, Leiden-Boston, 2017, ss. 418-429.

Frisk, Hjalmar; Griechisches Etymologisches Worterbuch, 3 vol., Heidelberg, 1969-72.

Kazhdan, Alexander, P.; “Isaiah”, The Oxford Dictionary of Byzantium, 2, New-York/Oxford: Oxford University Press, 1991 , ss. $1013-1014$. Kaya, İlkgül; "Paris Psalterionu (Cod. gr. 139, Paris-Ulusal Kütüphanesi) ve Makedonya Rönesansı”. (ed.) Çeken, M. - Giray, K.- Giray, M. - Sunay. S. Sanat ve Estetikte Asal Değerler Mekan Zaman, 2015, Ankara, 2015, ss. 209-225.

Lowden, John; Illuminated Prophet Books: A Study of Byzantine Manuscripts of the Major and Minor Prophets, Penn State University Press, Pennsylvania, 1990.

Meyer, Mati; "The Personification of Zion in Byzantine Psalters with Marginal Illustrations: Between Eschatological Hopes and Realia”, Ars Iudaica, 7, Bar-Illan University, 2009, pp. 7-22, figs. 1-3, 10.

R. H. Charles; Ascension of Isaiah, Adam and Charles Black, London, 1900.

Takiguchi, Mika; “The Prophet Book”, A Companion to Byzantine Illustrated Manuscripts, (Ed. Vasiliki Tsamakda), Brill, Leiden-Boston, 2017, ss. 246-257.

Van der Vorm-Croughsi Mirjam; "The Old Greek of Isaiah An Analysis of Its Pluses and Minuses”, The Old Greek of Isaiah, Vol. 61, Septuagint and Cognate Studies, 2014, (Ed. Wolfgang Kraus), Society of Biblical Literature: Atlanta.

Weitzmann, Kurt; The Miniatures of the Sacra Parallela, Parisinus Graecus 923 (Studies in Manuscript Illumination, 8), Princeton University Press, Princeton, 1979.

Zakharova, Anna; “The Original Cycle of Miniatures in the Trebizond Lectionary and Its Place in the Byzantine Tradition”, Rivista di Storla della Miniatura, (1995), 169-187.

Zenbilci, Kaya, İlkgül; “Bizans Sanatında Nadir Bir İsa Tiplemesi: Günlerin Eskisi (Ho Palaios Ton Hemeron)”. (ed.) Faozi F.-Sinanoğlu A. Biltek Uluslararası Bilim, Teknoloji ve Sosyal Bilimlerde Güncel Gelişmeler Sempozyumu, 2019, Ankara, 2019. ss. 20-42.

Ziegler, Joseph; Untersuchungen zur Septuaginta des Buches Isaias, ATA XII, 3; Münster: Aschendorff, 1934.

\section{Çevrimiçi Kaynaklar}

http://www.bl.uk/manuscripts/Viewer.aspx?ref=add_ms_19352_f192v

https://www.prlib.ru/en/node/465928

https://static1.squarespace.com/static/5006cb3dc4aa3dba77394b45/t/55b91f43e4b0b1e8d327ad1a/1438195523191/What+are+the+Major+Pr ophets+and+Minor+Prophets\%3F.pdf

https://www.behindthename.com/name/isaiah\#: :text=Meaning $\% 20 \% 26 \% 20$ History,referring\%20to\%20the\%20Hebrew\%20God. https://digi.vatlib.it/view/MSS_Chig.R.VIII.54 
https://digi.vatlib.it/view/MSS_Vat.gr.1153

https://art.thewalters.org/detail/14546

https://gallica.bnf.fr/ark:/12148/btv1b8452659r/f146.item.zoom

https://gallica.bnf.fr/ark:/12148/btv1b85935681/f520.item.zoom

https://www.doaks.org/resources/manuscripts-in-the-byzantine-collection/psalter-and-new-testament 